\title{
Três Mulheres Artistas: trajetórias em arte e educação
}

\author{
Tres Mujeres Artistas: trajetorias en arte y educación \\ Three Women Artists: trajectories in art and education
}

\author{
Luiza Alves de Macedo Tavares ${ }^{1}$ \\ Eduarda Gonçalves Schuster ${ }^{2}$ \\ Nadia da Cruz Senna ${ }^{3}$
}

\begin{abstract}
Resumo
O trabalho apresenta a pesquisa sobre três artistas plásticas de Pelotas que integram o projeto "As artistas do Sul: experiências lúdicas e educativas", junto ao grupo de pesquisa "Caixa de Pandora: Estudos em Arte, Gênero e Memória” (CNPq/UFPel). A investigação teórico/prática concentra o foco sobre as trajetórias e processos criativos, com intenção de produzir livros ilustrados e demais materiais paradidáticos voltados ao público infanto-juvenil. Maria Lídia Magliani, Seli Maurício e Arlinda Nunes foram selecionadas devido ao protagonismo inovador e engajado na cena artística e educativa em âmbito nacional e internacional. As três artistas, educadoras e empreendedoras deram origem aos primeiros protótipos confeccionados pelo grupo. A linha metodológica segue perspectivas abertas e plurais, próprias das pesquisas baseadas em arte. Concorrem neste fazer o levantamento das biografias, do acervo imagético, os encontros com as artistas, curadores, colecionadores e outros pesquisadores interessados; bem como a experimentação com materiais e técnicas, elaboração de projeto de design, realização de oficinas e mediações, avaliações dos resultados e testes de impressão. Temos optado por materiais propositivos que convocam a ação de professores e alunos em prol de uma educação transformadora e inclusiva, que busca dar visibilidade às mulheres artistas, comumente, "silenciadas" ou “esquecidas" pela história (PERROT, 2005).
\end{abstract}

Palavras-Chave: arte-educação; livros paradidáticos; mulheres artistas.

\section{Resumen}

El trabajo presenta la pesquisa sobre trés artistas plásticas de la ciudad de Pelotas que integran el proyecto "As artistas do Sul: experiências lúdicas e educativas", junto al grupo de pesquisa "A Caixa de Pandora: Estudos de Arte, Gênero e Memória (CNPq/UFPel). La investigación teórico/práctica concentra el foco sobre las trayectorias y procesos creativos con la intención de producir libros ilustrados y demás materiales complementarios didacticos destinados al público infanto-juvenil. Maria Lídia Magliani, Seli Maurício y Arlinda Nunes fueron seleccionadas debido al protagonismo innovador y envuelto en la escena artistica y educativa en el ambito nacional e internacional. Las tres artistas, educadoras y emprendedoras dieron origen a los primeros prototipos confeccionados por el grupo. La linea metodologica sigue perspectivas abiertas y plurales propria de las pesquisas basadas en arte. Compiten en esta tarea el levantamiento de las biografias, el acervo de las imágenes, los encuentros con las artistas, curadores, coleccionadores y otros pesquisadores interesados, así como la experiencia con materiales y técnicas, elaboración del proyecto de diseño, realización de talleres e intercambios de opiniones, evaluación de los resultados y testes de impresión. Hemos optado por materiales propositivos que convocan a la acción de profesores y alumnos en favor de una educación transformadora e inclusiva que busca dar visibilidad a las mujeres artistas, comunmente, "silenciadas" u "olvidadas" por la historia (PERROT, 2005).

\footnotetext{
${ }^{1}$ Acadêmica de Artes Visuais-Bacharelado, Bolsista IC/FAPERGS, Centro de Artes, Universidade Federal de Pelotas, Pelotas, RS, Brasil; luamata100@gmail.com

2 Acadêmica de Artes Visuais-Bacharelado, IC/UFPel, Centro de Artes, Universidade Federal de Pelotas, Pelotas, RS, Brasil; eduardagschuster@gmail.com

${ }^{3}$ Doutora em Ciências da Comunicação, Professora Associada Centro de Artes, Universidade Federal de Pelotas, Pelotas, RS, Brasil; alecrins@ @otmail.com
} 
Palabras claves: arte-educación; libro complementario didactico; mujeres artistas.

\begin{abstract}
The work presents the research about three women artists from Pelotas who are part of the project "The artists of the South: ludic and educational experiences", together with the research group "Caixa de Pandora: Estudos de Arte, Gênero e Memória"(CNPq/UFPel). The theoretical/practical research focuses on trajectories and creative processes, with the intention of producing illustrated books and other materials aimed at children. Maria Lídia Magliani, Seli Maurício and Arlinda Nunes were selected due to their innovative protagonism and engaged artistic and educational scene in national and international scope. The three artists, educators and entrepreneurs gave rise to the first prototypes made by the group. The methodological line follows open and plural perspectives, proper of the researches based on art. They compete in this survey of biographies, imagery, meetings with artists, curators, collectors and other interested researchers; as well as experimentation with materials and techniques, project design, workshops and mediations, results evaluations and print tests. We have opted for propositional materials that call for the action of teachers and students in favor of a transformative and inclusive education, that seeks to give visibility to women artists, who are commonly "silenced" or "forgotten" by history (PERROT, 2005).
\end{abstract}

Keywords: art education; books for children; women artists.

\title{
1. Introdução
}

O artigo apresenta o trabalho desenvolvido em torno de três mulheres artistas de Pelotas ressaltando a importância de suas trajetórias para a história e o ensino da arte na cidade. A produção sobre essas artistas, em fase de finalização, ocorre junto ao projeto $A s$ artistas do sul: experiências lúdicas e educativas, que tem continuidade com a investigação sobre outras artistas da região, previamente selecionadas. Nosso propósito é dar visibilidade as artistas através da pesquisa e da produção de material paradidático para o público infantojuvenil. O projeto está filiado ao grupo de pesquisa Caixa de Pandora: estudos de Arte, Gênero e Memória cadastrado junto ao $\mathrm{CNPq} / \mathrm{UFPel}$, que tem como missão a promoção do conhecimento sobre mulheres artistas, filósofas e educadoras. Buscamos nessa investigação revelar percursos e processos criativos das artistas visuais que construíram suas carreiras no sul do país, com intenção de trazer maior reconhecimento a estas artistas, tão pouco contempladas no meio acadêmico brasileiro. $\mathrm{O}$ foco do estudo recai sobre os embates em torno de identidades e subjetividades assumidas pela mulher, temas recorrentes nas representações e autorrepresentações do feminino protagonizado pelas artistas contemporâneas.

A abordagem metodológica segue a proposição emergente, conhecida como Artografia, pela relação indissociada que estabelece entre os papéis assumidos pelas artistas, professoras, pesquisadoras. Essa é uma perspectiva aberta e plural, própria das pesquisas baseadas em arte, permite a construção de modelos autorais, narrativas poéticas e objetos 
diferenciados como suporte e veículo da investigação conduzida. As etapas compreendem o levantamento das biografias, entrevistas com estudiosos e encontro com as artistas, estudo das obras e dos processos criativos, instrumentalização da equipe, seleção de materiais e técnicas, projeto gráfico e editorial, registro e documentação do processo investigativo, com todas as etapas percorridas, reuniões de avaliação, produção de material para apresentação em eventos acadêmicos e artísticos. Cabe esclarecer, que cada artista desencadeia um projeto de design exclusivo, baseado em seus processos criativos. Contudo, mantemos a linha de material propositivo, para os livros ilustrados individuais e temos um projeto para o conjunto da coleção, que será organizada em uma caixa box, a nossa Caixa de Pandora.

\section{As artistas do Sul}

As três artistas selecionadas para dar início à coleção foram Maria Lídia Magliani, Seli Maurício e Arlinda Nunes, três mulheres importantes pelo seu protagonismo na cena artística e educativa da cidade e região. Suas ações causaram transformações fazendo avançar questões políticas e inclusivas, surgimento de espaços expositivos, reformulação de projetos de ensino, organização de artistas em coletivos, instaurando e fomentando o sistema da arte e de seu ensino em espaços formais e informais.

\subsection{Maria Lídia Magliani (1946-2012)}

Magliani nasceu em Pelotas, mas logo cedo se mudou para Porto Alegre, onde concluiu sua formação, sendo a primeira mulher negra a se graduar no Instituto de Artes da Universidade Federal do Rio Grande do Sul, em 1966. Seu engajamento como mulher e artista nos provocou a redescobrir sua obra e percorrer sua trajetória, precocemente interrompida por conta de seu falecimento em 2012.

A artista que concentrava grande energia experimentou diversas linguagens artísticas, como o desenho, escultura, gravura, pintura, cenário, figurino, ilustração, diagramação para jornais e editoras e, inclusive, participou como atriz em espetáculos teatrais nos conturbados anos 70. As transformações políticas e artísticas incidem sobre sua obra de forma dramática e intensa, para ela não há distinção entre arte e vida.

A condição humana, o simbolismo dos objetos e a expressividade dos corpos são recorrentes em sua produção. Em torno dessas problemáticas a artista desenvolveu muitas séries onde experimentou diferentes materiais e técnicas investindo sobre seu processo criativo. Por todas estas distinções selecionamos Magliani como a primeira artista pelotense a integrar a coleção As Artistas do Sul (Figura 1). 


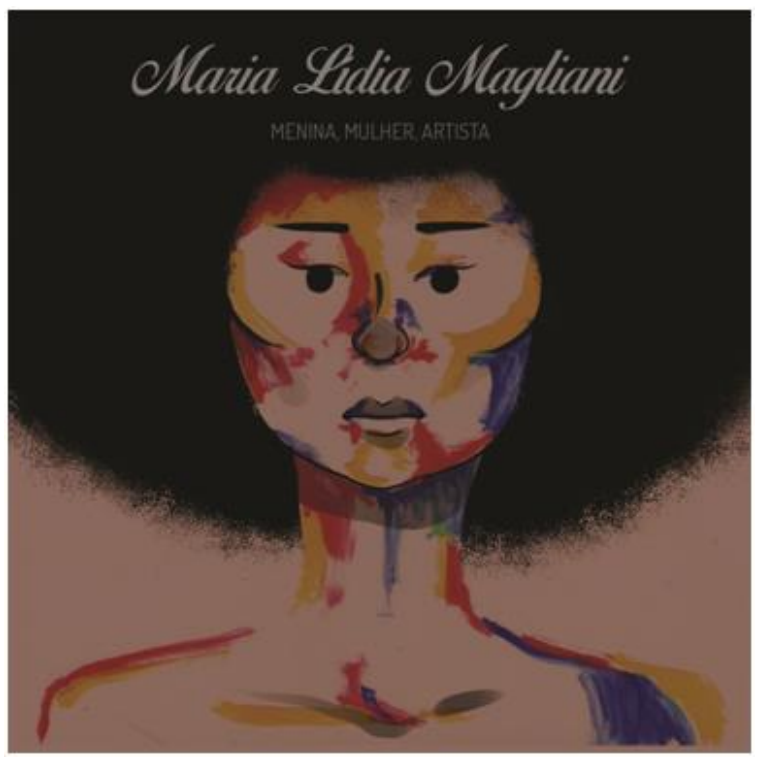

Figura 1 - Capa do livro paradidático de Magliani.

Fonte: Autor.

O livro ilustrado produzido pelo grupo constitui uma narrativa, eminentemente, visual, organizada em sequência, como nas histórias em quadrinhos. Selecionamos três momentos marcantes de sua vida, associados as descobertas e processos experimentados em três séries desenvolvidas.

$\mathrm{Na}$ primeira fase, comparece a menina Magliani que se diverte com os objetos do mundo doméstico, da série Acumulações construída em gravura. A fase seguinte apresenta a jovem adulta, que passeia pela rua e encontra encantadoras sombras, conforme se apresentam na série Mundaréu (Figura 2). Por fim, selecionamos os trabalhos da série Praia, que se desdobra numa página sanfonada e apresenta a artista como uma senhora madura que interage com as personagens que ela mesma criou e comparecem nas pinturas desenvolvidas nessa fase de sua vida. A partir destes trabalhos optamos por reconstruir algumas das imagens representadas em suas séries, utilizando carimbos confeccionados em EVA, os materiais e a técnica alcançaram resultados bem próximos dos obtidos em gravura pela artista, assim, propomos uma atividade pedagógica que integra o livro ilustrado, baseada nesse exercício, promovendo uma aproximação ao universo criativo da artista. 


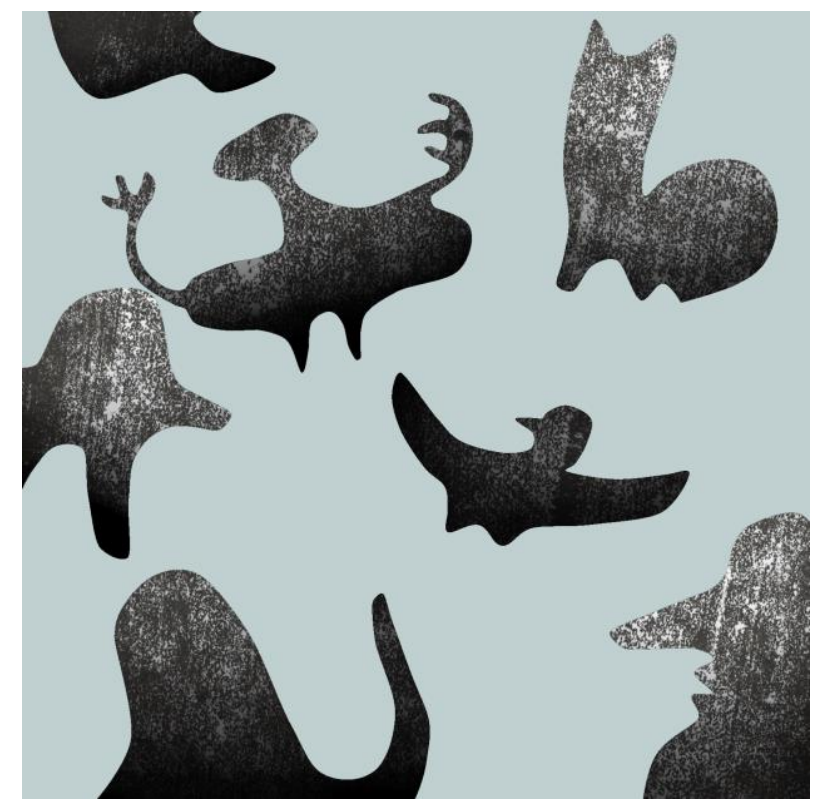

Figura 2 - Releitura da série Mundaréu para o livro.

Fonte: Autor

\subsection{Seli Nachtigall Maurício (1941)}

Engajada e atuante em projetos que repensam práticas de arte ligada às questões políticas e sociais, a artista bonequeira Seli Maurício, formada na antiga EBA e professora na Escolinha de artes de Pelotas foi a segunda artista que selecionamos para o projeto. Com uma produção que abrange diversas linguagens, a Tia Seli, como ficou conhecida, deu vida a fantoches e bonecos, que animaram festas, foram objetos de criação coletiva, ferramentas pedagógicas e contribuíram para revigorar o Teatro de Bonecos na região sul. A artista fundou o grupo Trio Pilha, o primeiro grupo de Pelotas a participar do Festival Internacional de Teatro de Bonecos de Canela, em 1998.

O vínculo com a natureza e seu amor pelas crianças lhe motivou a criar a Praça da Paz, que se instala em um terreno baldio ao lado da Igreja Nossa Senhora dos Navegantes, na Praia do Laranjal, Pelotas. A artista limpou, plantou, pintou murais, instalou objetos lúdicos e fez surgir um espaço de convivência para a comunidade, para aproximar as pessoas, ativar seus sentidos e sensibilidade estética. Com a passagem do tempo e a falta de Seli Maurício, devido a problemas de saúde, a natureza tomou conta, o verde dos murais ganhou o musgo da vegetação e alguns dos objetos se deterioram.

Como ação da pesquisa propomos um encontro com a artista na Praça da Paz, também convidamos uma turma de alunos da escola Barreto, no Laranjal, uma surpresa para ela. As crianças encheram o espaço com sua alegria e energia, animando nossa artista. Seli 
demonstrou seu amor pela natureza e carinho para com as crianças, propomos brincadeiras, desenhamos, trocamos memórias e afetos. Olhando para as fotografias e os desenhos realizados durante aquela tarde de sol, decidimos que o projeto gráfico deveria contemplar essa experiência, esse fazer coletivo, que traduz com perspicácia a sua poética (Figura 3).

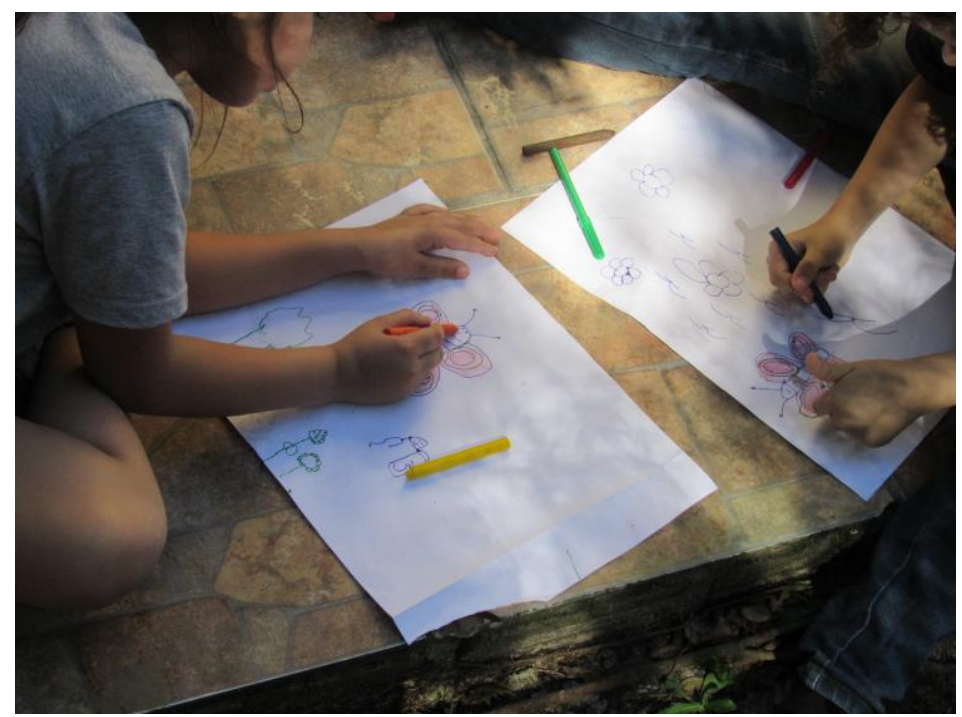

Figura 3 - Crianças desenhando na Praça da Paz.

Fonte: Autor.

O livro também foi feito em conjunto, os integrantes se organizaram para realizarem as ilustrações que conjugam os diferentes autores, em uma experiência onde uns desenharam o cenário, outros os personagens, entrando ainda os desenhos feitos pelas crianças durante o encontro. A edição foi determinante para integrar as produções, construindo ilustrações que captam a experiência de forma lúdica, para que a história fosse divertida e aberta a interpretações e explorações dos leitores (Figura 4). Ao final apresentamos Seli Maurício e o seu trabalho com um breve texto que reinventa com fantasia e sensibilidade a trajetória da artista.

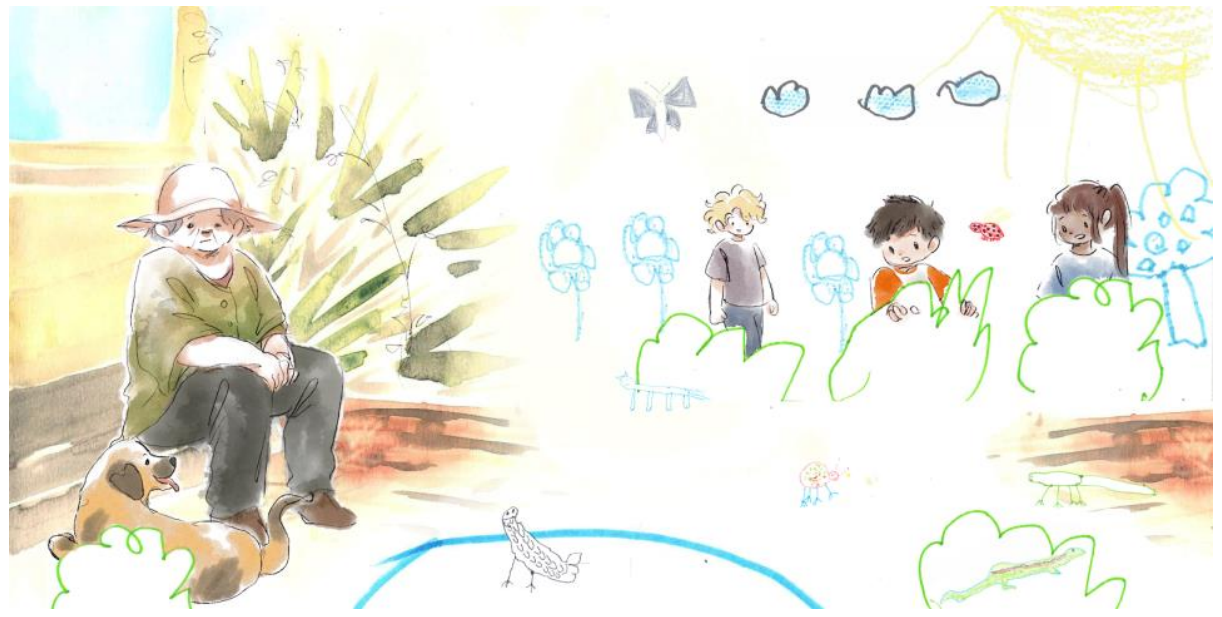

Figura 4 - Página do livro de Seli Maurício.

Fonte: Autor 


\subsection{Arlinda Nunes (1928)}

Arlinda Nunes, a terceira artista revisitada pelo grupo, nasceu em Pelotas, cidade onde construiu sua formação e iniciou sua carreira como artista visual e professora de artes no ensino fundamental. Ela fez parte da segunda turma da Escola de Belas Artes, tendo se formado em 1954. Possuindo enorme desejo de aprender, Arlinda Nunes fez cursos e diversas oficinas mesmo após graduar-se. Um desses cursos foi determinante para sua poética, o ministrado pela Inah Costa, uma artista também pelotense, porém com trânsito no cenário das artes do Rio de Janeiro, que promoveu o conhecimento de estéticas e artistas ligados aos movimentos artísticos de vanguarda. A partir desse curso Arlinda Nunes desenvolveu uma poética abstracionista e concretista.

As vanguardas artísticas demoraram a chegar ao sul do país, mas a curiosidade e atuação de Arlinda Nunes foram decisivas para mudar o cenário, seu engajamento alavancou e fez surgir o sistema das artes em Pelotas, inaugurando espaços expositivos, coletivos de artistas, organizações de eventos como salões de arte, cursos de arte e publicações. Dessa forma, seu protagonismo assertivo e intensivo contribuiu para que a cidade se destacasse como polo cultural do sul do país.

Arlinda Nunes também foi professora da Escola Assis Brasil, atuou na formação continuada para professores, fundou o Movimento Artístico de Pelotas (MAP) em 1976. Sua carreira atravessa fronteiras e vai alcançar reconhecimento internacional, recebe prêmios e se revela um sucesso de crítica e de público, suas obras estão espalhadas em acervos de museus, galerias, fundações e integram coleções particulares.

A professora e pesquisadora Carmen Diniz foi a curadora da grande retrospectiva "Arlinda Nunes: a trajetória de uma artista e sua atuação nas artes plásticas de Pelotas", ocorrida em julho de 2017, no Museu de Arte Leopoldo Gotuzzo. Em seu texto de apresentação da exposição ela destaca a inquietação que move a artista, sempre pronta para aprender, experimentar materiais, técnicas e enfrentar desafios poéticos. O projeto de curadoria da mostra retrospectiva procurou dar visibilidade a todas as fases artísticas de Arlinda Nunes. São mais de sete décadas dedicadas às artes plásticas, com investimento nas diferentes linguagens com igual vigor, seja no desenho, pintura, cerâmica, montagens e objetos. Foram muitos cursos, muitos trabalhos, diferentes fases, distribuídos por uma numerosa participação em exposições. 
No início de março de 2018 realizamos uma entrevista com a artista, podemos ver os álbuns de recortes de notícias e fotografias, ela nos esclareceu sobre materiais e técnicas experimentados durante as aulas com Inah Costa. Principalmente, nas séries em que domina um desenho gestual que origina uma figura expressiva, de contornos marcados em preto, escolhido como processo poético para ser explorado por nós nas ilustrações e no design gráfico do livro sobre a artista.

O livro foi construído a partir de um roteiro baseado em sua trajetória narrada, pela própria artista nos dias de hoje, abrindo um álbum de fotos, passando desde o momento em que estudou nas Belas Artes, sem compreender a arte moderna, encontrando Inah Costa, aprendendo sobre a arte moderna, seus tempos como professora e artista, e o livro termina com a imagem dela fechando o álbum. Mas ao longo da elaboração surgiu a ideia de que apesar de manter as figuras e a mesma configuração em todas as páginas, estas não seriam costuradas numa ordem e se optou pelas páginas estarem soltas, permitindo que o leitor pudesse montar na ordem que lhe fosse mais divertida. Com isso a proposta do livro não se limitou só no ensino de sua técnica como incentiva a criança exercitar sua imaginação narrativa (Figura 5).

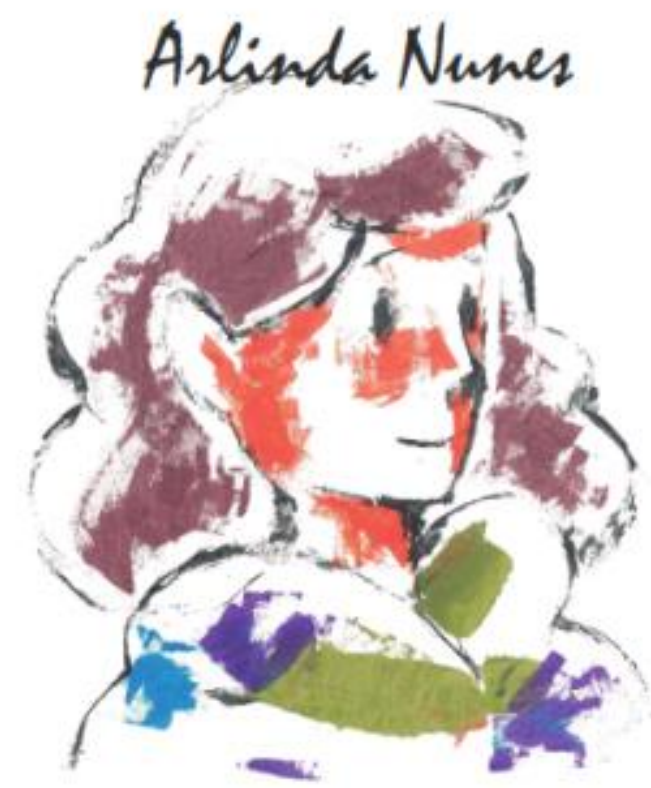

Figura 5 - Capa do livro de Arlinda Nunes.

Fonte: Autor.

\section{Conclusões}


O projeto tem proporcionado grande aprendizado sobre essas artistas, seus processos e vivências. Temos nos instrumentalizado em técnicas e aprendido sobre processos criativos autorais, avançamos nos estudos sobre arte e gênero, inclusive adquirimos bibliografia para incrementar nossa Biblioteca Setorial, com recursos aprovados junto ao CNPq.

Experimentamos fazeres, fruições e ações educativas em torno da arte produzida por essas mulheres artistas, que apesar de impactarem e fazerem avançar a arte e a cultura, principalmente, em suas regiões, permanecem pouco conhecidas. Cabe a nós, mulheres, artistas, pesquisadoras resgatarmos esses protagonismos, dar a ver processos e produções e promovermos o reconhecimento e sua inserção na história da arte. Ao longo do estudo, vamos descobrindo outras artistas, que se interligam umas às outras, seja pelas parcerias que estabeleceram, seja pelo legado artístico e educativo que nos deixaram. Assim, devem integrar nossa coleção as trajetórias de Inah D’Ávila Costa, Hilda Mattos, Benette Casaretto Motta, Helena Pinto Ferreira, Lenir de Miranda, Aurys Abrantes e Myriam Anselmo.

\section{Referências}

ARRUDA, Lina Alves. Revisões feministas das histórias da arte: contribuições de Linda Nochlin e Griselda Pollock. In: LODO, Gabriela. VII Encontro de História da Arte: os caminhos da história da arte desde Giorgio Vasari. Campinas, SP : UNICAMP/BC/IA, 2012, p. $250-255$.

DINIZ, Carmen Regina Bauer. Nos descaminhos do imaginário: a tradição acadêmica nas artes pláticas de Pelotas. 1996. Dissertação - Curso de Pós Graduação em Artes Visuais, Instituto de Artes, Universidade Federal do Rio Grande do Sul, Porto Alegre, 1996.

DINIZ, Carmen Regina Bauer. (Coord.). Arlinda Nunes: a trajetória de uma artista e sua atuação nas artes plásticas de Pelotas. Pelotas: Museu de Arte Leopoldo Gotuzzo, 2017.

IRWIN, Rita L., \& de COSSON, Alex. (Eds.). A/r/tography: Rendering self through artsbased living inquiry. Vancouver: Pacific Educational Press. 2004.

PERROT, Michele. As mulheres ou os silêncios da história. Tradução: Viviane Ribeiro. Bauru, SP: editora EDUSC, 2005.

POLLOCK, Griselda. Encuentros en el museo feminista virtual. Madrid, Ediciones Cátedra, 2010.

ROSA, Renato; PRESSER, Décio. Dicionário Artes Plásticas no Rio Grande do Sul. 2 ed. Porto Alegre: Editora da Universidade Federal do Rio Grande do Sul/UFRGS, 2000.

ROSA, Renato (org.). Magliani a solidão do corpo. Porto Alegre: Pinacoteca Aldo Locatelli, 2013. Catálogo da exposição de Maria Lídia Magliani. 
SANTO, Anaizi Cruz Espírito; DINIZ, Carmem Regina Bauer; MAGALHÃES, Clarice Rego (org.). A Escola de Belas Artes de Pelotas - Memória e História. Pelotas: Ed. UFPel, 2014.

SILVA, Ursula Rosa; LORETO, Mari Lúcie. História da arte em Pelotas: a pintura de 1870 a 1080. Pelotas: EDUCAT, 1996. 